http://jmscr.igmpublication.org/home/ ISSN (e)-2347-176x ISSN (p) 2455-0450 crossref DOI: https://dx.doi.org/10.18535/jmscr/v7i8.61

\title{
The distribution of Prevalence of Vitamin D deficiency among children with moderate and severe wasting residing in Himalayan region
}

\author{
Authors \\ Dr Ambuj Shandil ${ }^{1}$, Dr Pooja Thakur ${ }^{2}$, Dr Vijay Kumar Sauhta ${ }^{3}$, \\ Dr Abhinay Sharma ${ }^{4}$, Dr Ishan Chauhan ${ }^{5}$, Dr Kalpana Sharma ${ }^{6}$, \\ Dr Arnav Shandil ${ }^{7 *}$, Dr Daleep Tegta ${ }^{8}$ \\ ${ }^{1}$ MD Pediatrics PGIMER, Chandigarh (India) \\ 2,3,4,5,6,7,8 MD Civil Hospital Theog, Distt Shimla, Himachal Pradesh (India) \\ *Corresponding Author \\ Dr Arnav Shandil, MD \\ Civil Hospital Theog, Shimla H.P (India)
}

\begin{abstract}
Background: Vitamin $D$ is important for the skeletal maturation of children. High altitude areas are known to be endemic for vitamin $D$ deficiency, partly due to less exposure to sunlight and mostly due to predominant indoor activities of children. Toddlers and preschool children are at higher risk for nutritional deficiencies due to increased requirements and poor nutrition.

Objective: To access the prevalence of vitamin D deficiency in poorly growing children.

Methods: This was a single-centre retrospective study done in the out-patient department of Civil hospital Theog. A total of 110 children between 1 to 5 years of age were enrolled over a period of December 2017 to November 2018 with the purpose of finding prevalence of vitamin D deficiency in poorly growing children.

Results: A total of 110 children between 1 to 5 years of age were studied. They were grouped into in two weight/height bands and vitamin D levels were estimated in both the groups. In $1^{\text {st }}$ group (weight/height $z$ score -1 to -3 z score, as per WHO growth charts), among 68 children enrolled, vitamin D levels were found to be insufficient in55\% (15/27) males and $51 \%$ (21/41) females whereas, it was found to be deficient in $11 \%$ (3/27) males and $9 \%$ (4/41) females. In second the group (weight/height $z$ score $Z<-3$ as per WHO growth charts), among 42 children, vitamin D levels were found to be insufficient in 39\% (7/18) males and 37\% (9/24) females whereas, it was found to be deficient in 56\% (10/18)males and $58 \%$ (14/24)females.

Conclusion: We concluded that, the prevalence of Vitamin D deficiency is significantly more in severely wasted children as compared to child with no or moderate wasting. In this study however, we did not test for any other nutritional deficiencies.
\end{abstract}

\section{Introduction}

Vitamin D deficiency is one of the most common nutritional deficiencies in world $^{(1)}$. It is epidemic all over the Indian subcontinent, with a prevalence of $70 \%-90 \%$ in the general population ${ }^{(2)}$. It is estimated that more than 1 billion people worldwide have vitamin $\mathrm{D}$ deficiency or insufficiency $^{(3)}$ where, Vitamin D deficiency is 
defined as serum Vitamin D levels less than $<10$ $\mathrm{ng} / \mathrm{ml}$ and levels between 10-20 $\mathrm{ng} / \mathrm{ml}$ are defined as Vitamin D insufficiency. In India, widely consumed food items such as dairy products are rarely fortified with vitamin D. Indian socioreligious and cultural practices do not facilitate adequate sun exposure, thereby negating potential benefits of abundant sunshine. Consequently, subclinical vitamin $D$ deficiency is highly prevalent in both urban and rural settings, and across all socioeconomic and geographic subdivisions $^{(2)(4)}$. Vitamin D deficiency is likely to play an important role in the very high prevalence of rickets, osteoporosis, cardiovascular diseases, diabetes, cancer and infections such as tuberculosis in India. Fortification of staple foods with vitamin $\mathrm{D}$ is the most viable population based strategy to achieve vitamin D sufficiency. Unfortunately, even in advanced countries like USA and Canada, food fortification strategies with vitamin D have been only partially effective and have largely failed to attain vitamin D sufficiency. Our study reviews the status of vitamin D nutrition in the sub Himalayan region of Indian subcontinent and also the underlying causes for this epidemic. Implementation of population based educational and interventional strategies to combat this scourge require recognition of vitamin D deficiency as a public health problem by the governing bodies so that the healthcare funds can be allocated appropriately.

Serum Vitamin D levels have been found to be low among non-western immigrant populations in European countries compared to indigenous European populations ${ }^{(5)}$ This may lead to differences in health and well-being of this population group . Consequences of vitamin D deficiency include bone- and muscle-related symptoms (e.g., bone and muscle pain), decreased muscle strength, and diseases (e.g., rickets in children; osteomalacia in adults) ${ }^{(6)}$ Other possible consequences are diabetes mellitus, infectious diseases, and cancer ${ }^{\text {(7).(8)(9)(10) }}$

Direct sunlight stimulates the production of vitamin D in the skin from 7-dehydrocholesterol.
Other sources of vitamin D include some natural foods (e.g., fatty fish), fortified foods (e.g., margarine), and supplements. The amount of vitamin D produced through exposure to UV-B radiation depends on skin type: the darker the skin, the more sunlight is required to produce a given amount of vitamin $\mathrm{D}^{(11)(12)}$. Non-western immigrants usually have darker skin than indigenous European subjects. Therefore, they have low serum 25-hydroxyvitamin D (25(OH)D) levels, even after living at the same latitude.

The duration of UV-B radiation exposure required to produce a certain quantity of vitamin $\mathrm{D}$ in a particular skin surface depends upon on the season, time of the day, and the geographical location $^{(13)(14)}$ The higher the latitude, the lower the UV-B intensity, and the fewer months and hours per day during which vitamin $\mathrm{D}$ is produced. Most European countries are located at a higher latitude than the countries of origin of non-western immigrants.

The threshold for vitamin D deficiency should ideally be based on its consequences. Our aim was to compare the vitamin D status of children residing in sub-Himalayan region additionally, we wished to identify determinants which could explain the differences in vitamin D levels between subgroups in the studied populations.

\section{Material and Methods}

This was a retrospective study done in the outpatient department of Civil hospital Theog. A total of 110 children between 1 to 5 years of age were studied from December 2017 to November 2018. The purpose was to find prevalence of vitamin $\mathrm{D}$ deficiency in wasted children. The enrolled children were divided into two groups based on their weight/height as per WHO reference growth standards. Group 1 had weight/height $\mathrm{z}$ score between -1 to $-3 \mathrm{z}$, as per WHO charts and group 2 had $\mathrm{z}$ score $<-3 \mathrm{Z}$ as per WHO charts. Vitamin D $\left(25[\mathrm{OH}] \mathrm{D}_{3}\right)$ levels were measured using High Performance Liquid Chromatography (HPLC). 


\section{Results}

A total of 110 children between ages 1 to 5 years were enrolled in our Civil Hospital. Among them there were $65(59 \%)$ females and $45(40 \%)$ males.

\section{total number of enrolled patients}

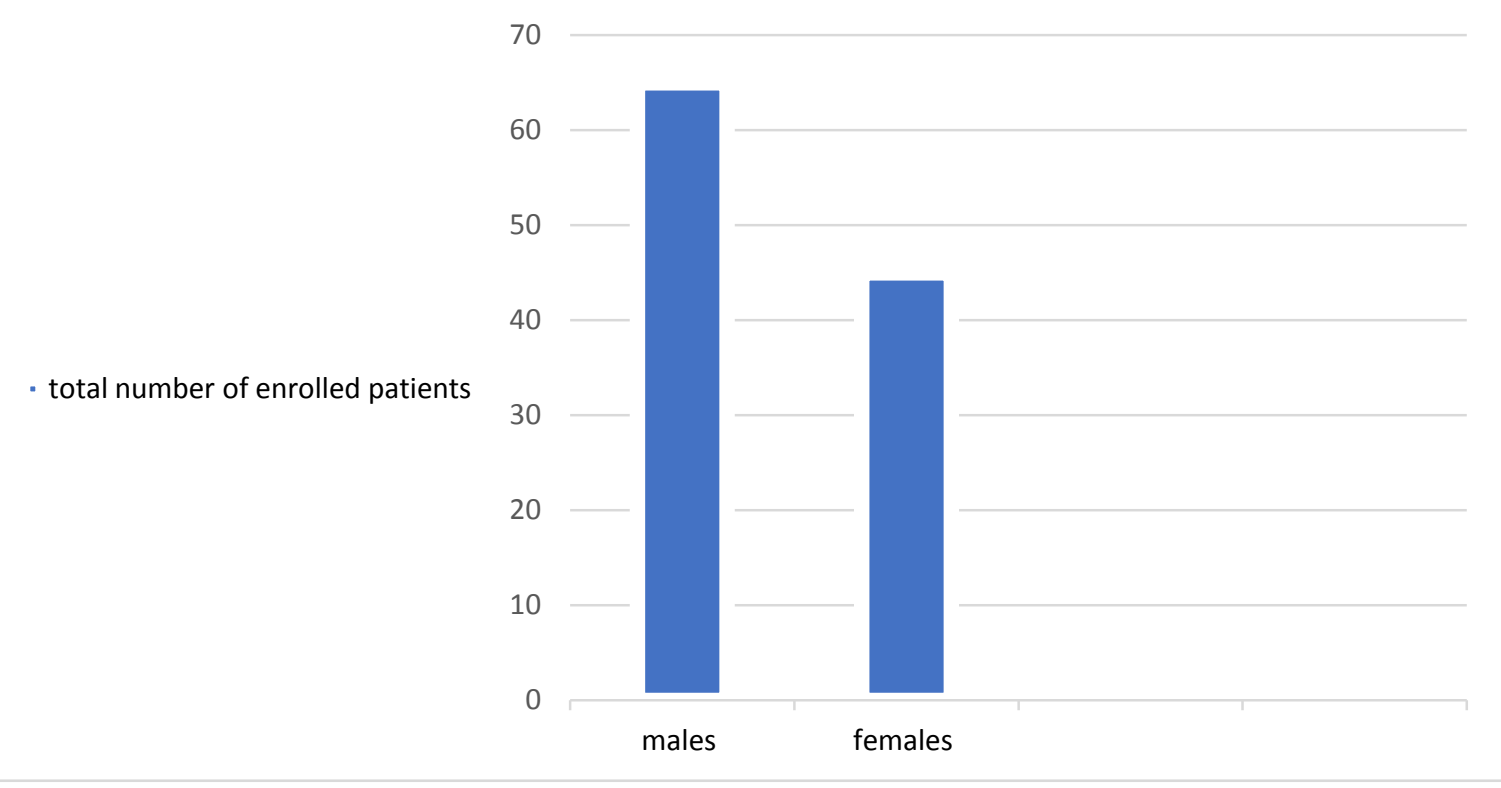

Fig.1 Age Distribution of enrolled subjects in study

Among the 45 male children; 27/45(60\%) were having weight/height $\mathrm{Z}$ score between -1 to-3Z as per WHO reference growth standards and 18/45 $(40 \%)$ had weight/height <-3Z (as per WHO growth reference standards). Out of 65 females enrolled, 41/65 (63\%) were having weight/height $\mathrm{Z}$ score between -1 to-3Z and 24/65 (37\%) had weight/height <-3Z (as per WHO growth reference standards).

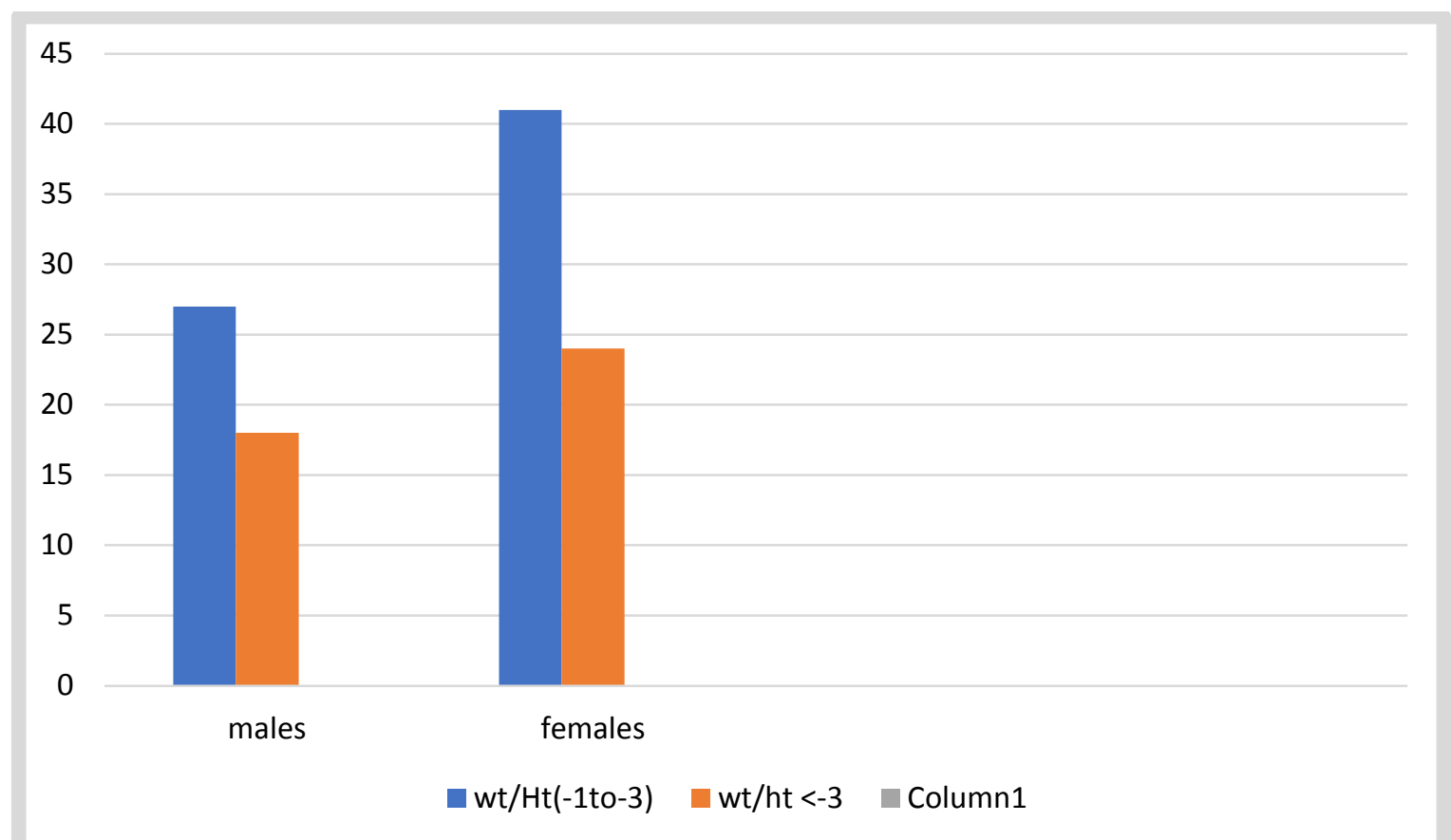

Fig. 2 Distribution of enrolled children depending upon sex and weight/height z score as per WHO growth reference standards 
The levels of vitamin D were compared between the two groups. In the first group, with weight/height between -1 to $-3 \mathrm{z}$ score, we found that, only 9/27(33\%) males and 16/41(39\%) females were having vitamin D levels $>20 \mathrm{ng} / \mathrm{ml}$.
$15 / 27(55 \%)$ males and 21/41(51\%) females were having vitamin D levels between 10-20 ng/ml whereas only $3 / 27(11 \%)$ males and 4/41(9\%) females were having severe vitamin D deficiency with levels below $10 \mathrm{ng} / \mathrm{ml}$.

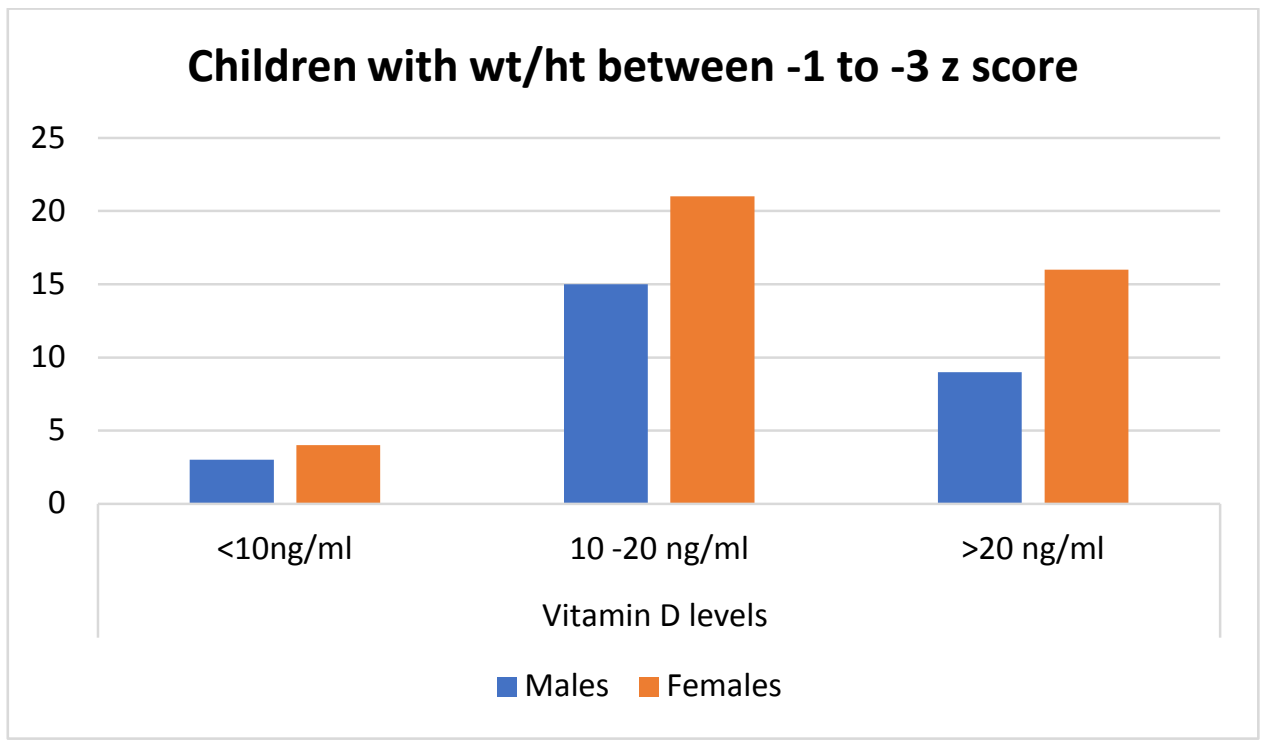

Fig. 3 Distribution of Serum Vitamin D levels among children in Group 1 (weight/height -1 to -3 z score).

In children in the second group (weight/height <$3 Z$ score); only $1 / 18$ males (5.5\%) and $1 / 24$ females $(4 \%)$ were having vitamin D levels above $20 \mathrm{ng} / \mathrm{ml}$ suggesting other possible etiology. Vitamin D insufficiency was found in $7 / 18(39 \%)$ males and 9/24(37\%) female children. In our study, we found that most of the children of both sexes with weight/height $<-3 z$ score were also having vitamin D levels $<10 \mathrm{ng} / \mathrm{ml}$ with as many as $10 / 18(56 \%)$ males and $14 / 24(58 \%)$ females.

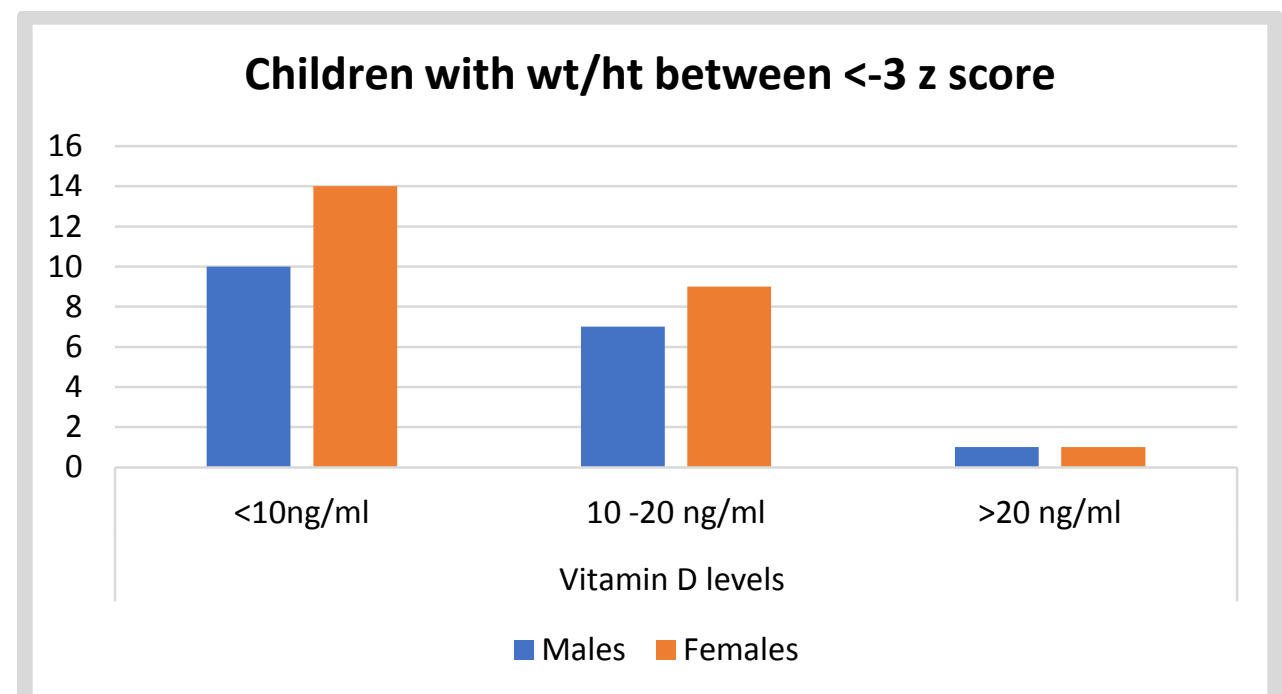

Fig. 4 Distribution of Serum Vitamin D levels among children in Group 1 (weight/height -1 to -3 z score).

Thus, among 110 enrolled children a total of 31 (28\%) children were found to be vitamin D deficient and $52(47 \%)$ children were Vitamin D insufficient with combined prevalence (i.e deficient plus insufficient) of $75 \%$ (83/110). 


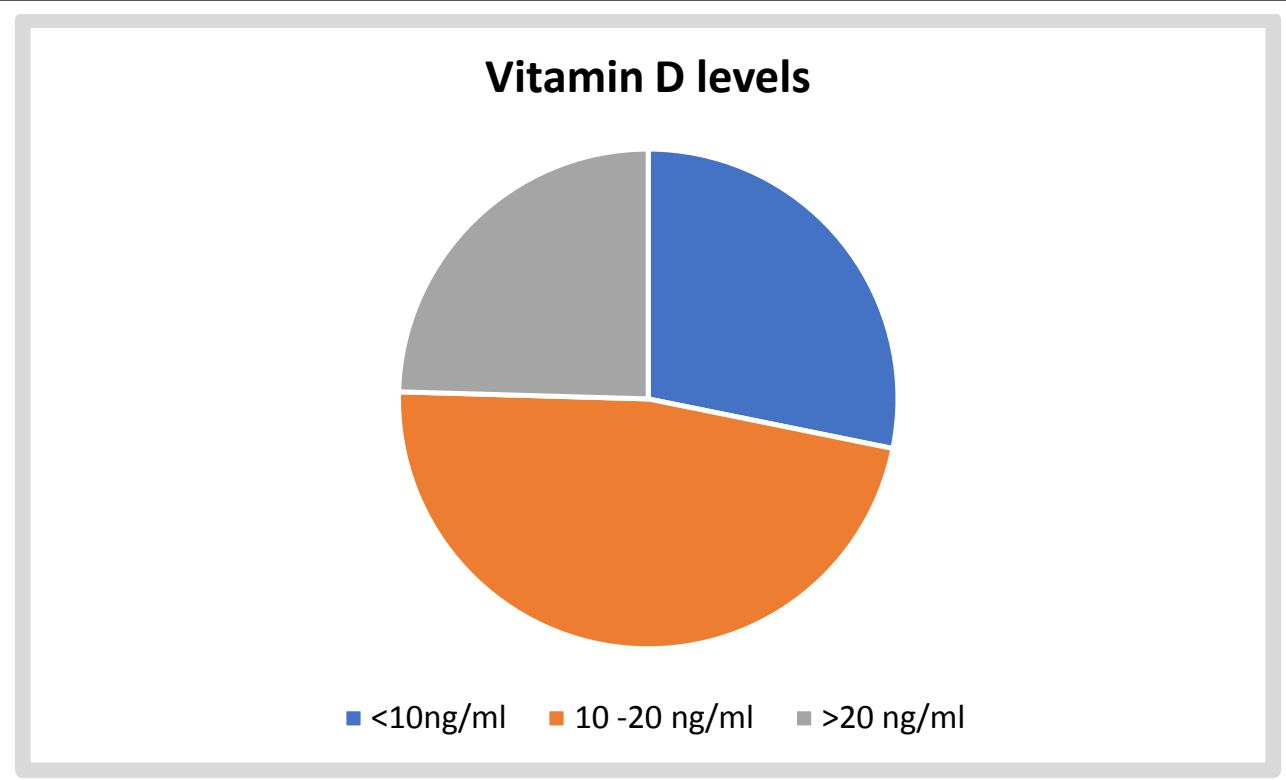

Fig 5. Overall distribution of Vitamin D levels in enrolled population

\section{Discussion}

High altitude areas are known to be endemic for low vitamin D levels partly due to less exposure to sunlight and mostly indoor activities of children. Hirschler et al in their study demonstrated a high prevalence of both $25(\mathrm{OH}) \mathrm{D}_{3}$ deficiency and insufficiency and an inverse association between $25(\mathrm{OH}) \mathrm{D}_{3}$ in apparently healthy children living in high altitudes ${ }^{(15)}$

The purpose of our study is to evaluate the presence of vitamin $\mathrm{D}$ deficiency in children between 1 to 5 years of age that presented with poor weight/height and residing at high altitude. In our study, we found that most of the children of both sexes with weight/height $<-3 z$ score were having vitamin D levels $<10 \mathrm{ng} / \mathrm{ml}$ including $56 \%$ males and $58 \%$ females. A similar study was conducted by Mokhtar RR et al in children between 6 months to 3years of age, which concluded that children who were underweight were more likely to have serum $25(\mathrm{OH}) \mathrm{D}_{3}<42 \cdot 5$ $\mathrm{nmol} / \mathrm{l}$ (adjusted OR $(\mathrm{aOR})=2 \cdot 0 ; 95 \%$ CI $1 \cdot 2$, $3 \cdot 3)$. Children with low serum $25(\mathrm{OH}) \mathrm{D}_{3}$ levels were more likely to be stunted $(\mathrm{aOR}=2 \cdot 8 ; 95 \%$ CI 1.6, 4.7). ${ }^{(16)}$ These findings were in support of our study. Walli NZ et al showed severe vitamin $\mathrm{D}$ deficiency in malnourished children below 5 years $^{(17)}$. Ejaz MZ et al also stated rickets as a second major cause of stunting in his study involving as much as $36 \%$ of their patients ${ }^{(18)}$. Kensarah OA et al. stating 63\% children and toddlers suffer from vitamin D deficiency in their study ${ }^{(19)}$

We did not evaluate for sociodemographic factors leading to poor growth and vitamin D deficiency however, many studies in literature suggest positive correlation for the same ${ }^{(20)}$. We also did not evaluate for other micronutrient deficiencies that can co-exist with vitamin D deficiency.

\section{Conclusion}

This study lead to the conclusion to that there is very high prevalence of Vitamin D deficiency in children residing at high altitudes and the prevalence is all the more in children who are severely wasted, thus, necessitating the need of food fortification and vitamin D supplementation in this region.

\section{References}

1. Vitamin D: extraskeletal health. - PubMed - NCBI [Internet]. [cited 2019 Jul 12]. Available from: https://www.ncbi.nlm.nih.gov/pubmed/?ter $\mathrm{m}=$ Holick + MF.+Vitamin $+\mathrm{D} \% 3 \mathrm{~A}+$ extrask eletal+health.+Rheum+Dis+Clin+North + A m. +2012 
2. Vitamin D status in India--its implications and remedial measures. - PubMed - NCBI [Internet].[cited2019Jul12].Availablefrom: https://www.ncbi.nlm.nih.gov/pubmed/?ter $\mathrm{m}=$ Harinarayanan $+\mathrm{CV} \% 2 \mathrm{C}+\mathrm{Joshi}+\mathrm{SR} .+\mathrm{V}$ itamin+D+status+in+India-

Its+implications+and+remedial+measures. +J+Assoc+Physicians.+2009

3. Holick MF. The Death D-fying Vitamin. Mayo Clin Proc. 2018;93(6):679-81.

4. Vitamin D \& bone mineral density of healthy school children in northern India. PubMed - NCBI [Internet]. [cited 2019 Jul 12]. Available from: https://www.ncbi.nlm.nih.gov/pubmed/?ter $\mathrm{m}=$ Marwaha+RK\%2C+Sripathy+G.+Vita min + D+and+Bone+mineral+density + of $+h$ ealthy+school+children+in+northern+Indi a.+Indian+J+Med+Res.+2008

5. Prevalence of vitamin $D$ deficiency among Turkish, Moroccan, Indian and sub-Sahara African populations in Europe and their countries of origin: an o... - PubMed NCBI [Internet]. [cited 2019 Jul 12]. Available from: https://www.ncbi.nlm.nih.gov/pubmed/?ter $\mathrm{m}=$ Prevalence+of+vitamin+D+deficiency +among+Turkish\%2C+Moroccan\%2C+In dian+and+sub-

Sahara+African+populations+in+Europe+ and+their+countries+of+origin $\% 3 \mathrm{~A}+\mathrm{an}+\mathrm{o}$ verview

6. [Rickets/Osteomalacia. Non-skeletal effects of vitamin D.] - PubMed - NCBI [Internet]. [cited 2019 Jul 12]. Available from:

https://www.ncbi.nlm.nih.gov/pubmed/302 69118

7. Nam H-K, Rhie Y-J, Lee K-H. Vitamin D level and gene polymorphisms in Korean children with type 1 diabetes. Pediatr Diabetes. 2019 Jun 17;

8. Vitamin D deficiency and diabetes. PubMed - NCBI [Internet]. [cited 2019 Jul 12]. Available from: https://www.ncbi.nlm.nih.gov/pubmed/283 41729

9. Pubmeddev, M MR and M. Extra-Skeletal Effects of Vitamin D. - PubMed - NCBI [Internet]. [cited 2019 Jul 12]. Available from:

https://www.ncbi.nlm.nih.gov/pubmed/312 52594

10. The Correlation between Serum Level of Vitamin D and Outcome of Sepsis Patients; a Cross-Sectional Study.PubMed - NCBI [Internet]. [cited 2019 Jul 12]. Available from: https://www.ncbi.nlm.nih.gov/pubmed/308 47436

11. The Impact of UV-dose, Body Surface Area Exposed and Other Factors on Cutaneous Vitamin D Synthesis Measured as Serum 25(OH)D Concentration: System... - PubMed - NCBI [Internet]. [cited 2019 Jul 12]. Available from: https://www.ncbi.nlm.nih.gov/pubmed/293 74754

12. Vitamin D production after UVB exposure - a comparison of exposed skin regions. PubMed - NCBI [Internet]. [cited 2019 Jul 12]. Available from: https://www.ncbi.nlm.nih.gov/pubmed/255 94723

13. Seasonal variations in serum vitamin $D$ according to age and sex. - PubMed NCBI [Internet]. [cited 2019 Jul 12]. Available from: https://www.ncbi.nlm.nih.gov/pubmed/240 09930

14. Ultraviolet light may contribute to geographic and racial blood pressure differences. - PubMed - NCBI [Internet]. [cited 2019 Jul 12]. Available from: https://www.ncbi.nlm.nih.gov/pubmed/926 0973

15. Hirschler V, Maccallini G, Molinari C, Aranda C, San Antonio de los Cobres Study Group. Low vitamin D concentrations among indigenous 
Argentinean children living at high altitudes. Pediatr Diabetes. 2013 May;14(3):203-10.

16. Mokhtar RR, Holick MF, Sempértegui F, Griffiths JK, Estrella B, Moore LL, et al. Vitamin D status is associated with underweight and stunting in children aged 6-36 months residing in the Ecuadorian Andes. Public Health Nutr. 2018;21(11):1974-85.

17. Walli NZ, Munubhi EK, Aboud S, Manji KP. Vitamin D Levels in Malnourished Children under 5 Years in a Tertiary Care Center at Muhimbili National Hospital, Dar es Salaam, Tanzania-A Crosssectional Study. J Trop Pediatr. 2017 01;63(3):203-9.

18. Ejaz MS, Latif N. Stunting and micronutrient deficiencies in malnourished children. JPMA J Pak Med Assoc. 2010 Jul;60(7):543-7.

19. Kensarah OA, Jazar AS, Azzeh FS. Hypovitaminosis D in Healthy Toddlers and Preschool Children from Western Saudi Arabia. Int J Vitam Nutr Res Int Z Vitam- Ernahrungsforschung J Int Vitaminol Nutr. 2015;85(1-2):50-60.

20. Voortman $T$, van den Hooven EH, Heijboer AC, Hofman A, Jaddoe VW, Franco OH. Vitamin D deficiency in school-age children is associated with sociodemographic and lifestyle factors. J Nutr. 2015 Apr;145(4):791-8. 